\title{
O Brincar e o Ensino da Linguagem Escrita na Educação Infantil: (In)Pressão dos Pais
}

\section{Playing and Teaching Written Language in Childhood Education: Parents' (In) Pressure}

\author{
Odete Selva*ab; Edione Teixeira de Carvalho ${ }^{\mathrm{a}}$; Geysa Luiza de Souza Santos ${ }^{\mathrm{a}}$; Antonio Gomes ${ }^{\mathrm{c}}$
}

\author{
${ }^{a}$ Instituto Federal de Educação, Ciência e Tecnologia de Mato Grosso, Programa de Pós-Graduação Stricto Sensu em Ensino. MT, Brasil. \\ 'Secretaria Municipal de Educação de Campo Verde. MT, Brasil. \\ 'Secretaria Municipal de Educação de Pontes e Lacerda. MT, Brasil \\ *E-mail: odete_selva@hotmail.com
}

\begin{abstract}
Resumo
Em nome de muitos "modismos" pedagógicos se sacrifica a infância com práticas inadequadas à fase da criança, desrespeitando seu modo de ser e sua linguagem própria, que é o brincar. Este artigo resulta de uma pesquisa realizada no Centro Educacional Amerecilda Conceição Fernandes Rezende, no município de Campo Verde (MT), com o objetivo de averiguar na percepção dos pais a importância que estes atribuem para o ensino da linguagem escrita e do brincar na Educação Infantil. Discute-se na problemática se há pressão por parte dos pais para que os professores iniciem o ensino da linguagem escrita nas fases de Pré I, II e III (4 a 6 anos) e se os professores sentem ou não tal pressão. Nesta trajetória se buscou traduzir a posição dos pais a respeito do problema, bem como o posicionamento dos professores. A metodologia considerada nesta investigação é de natureza aplicada, com uma abordagem quantitativa, no sentido de quantificar os dados e qualitativa no sentido de explicar a realidade pesquisada. Quanto aos objetivos é descritiva, e quanto aos procedimentos técnicos se caracteriza como pesquisa de campo. Os dados foram coletados mediante a aplicação de questionário com uma amostra de cinquenta e quatro pais e entrevistas coletivas e individuais com sete professores. Ao finalizar a pesquisa, conclui-se que há uma pressão implícita, por parte dos pais, e que os professores sentem essa pressão de várias fontes, até mesmo deles próprios.
\end{abstract}

Palavras-chave: Cuidar. Educar. Ensinar.

\begin{abstract}
In the name of many pedagogical "fads", childhood is sacrificed with practices inappropriate to the child's stage, disrespecting their way of being and their own language, which is playing. This article is the result of a research carried out at Centro Educacional Amerecilda Conceição Fernandes Rezende, in the municipality of Campo Verde (MT), with the aim of ascertaining in the parents' perception the importance they attach to the teaching of written language and playing in early childhood education. . The issue is discussed whether there is pressure on the parents' part for teachers to start teaching written language in the Pre I, II and III phases (4 to 6 years) and whether or not teachers feel such pressure. In this trajectory, it was sought to translate the parents 'position regarding the problem, as well as the teachers'position. The methodology considered in this investigation is of an applied nature, with a quantitative approach, in order to quantify the data and qualitative in order to explain the researched reality. As for the objectives, it is descriptive, and for technical procedures, it is characterized as field research. Data were collected through the application of a questionnaire with a sample of fifty-four parents and collective and individual interviews with seven teachers. At the end of the research, it is concluded that there is an implicit pressure from parents and that teachers feel this pressure from several sources, even from themselves.
\end{abstract}

keywords: Caring. Educating. Teaching

\section{Introdução}

O estudo traz uma discussão de caráter teórico-prático sobre o brincar e o ensino da linguagem escrita na Educação Infantil na visão dos pais. Essa discussão foi articulada para se refletir sobre as expectativas dos pais diante da escola e das pressões que realizam (ou não) aos professores, mesmo que de forma implícita e, se os professores têm sentido esta pressão, ou se de fato essa existe. Saber até que ponto os professores se sentem pressionados pelos pais para que haja um ensino da linguagem escrita, pelo menos em seus rudimentos nas classes de Pré I (4 anos), Pré II (5 anos) e Pré III (6 anos, antigo primeiro ano) pertencentes as fases de Pré-escola da Educação Infantil. Hipoteticamente, se percebem muitos impasses e indefinições que permeiam a prática pedagógica nesta etapa educativa, que se relacionam, basicamente, com duas ações intrínsecas à Educação Infantil, que vai além do cuidar; o brincar e o ensinar, os quais são indissociáveis.

Este artigo, resultado de uma pesquisa realizada em 2013, teve como principal objetivo analisar na percepção dos pais, em que medida o brincar e o aprender a linguagem escrita representa um problema que resulta em expectativas não satisfatoriamente resolvidas ou alcançadas pela escola em relação às crianças.

Nem sempre o ato de garantir a aprendizagem da escrita para crianças, na faixa etária entre $4 / 6$ anos, acontece sem problemas, em função dos muitos impasses de ordem pedagógica, de definição de proposta pedagógica, de apoio 
político e até de formação profissional. Um desses, o sacrifício da própria infância, em prol de uma sociedade que "pressiona" os pais para que a criança aprenda, logo, a ler e escrever (com um peso especial da mídia, nessa pressão). Em nome de muitos "modismos" pedagógicos, sacrifica-se a infância com práticas que nem ensinam realmente com significado e nem respeitam os modos de ser da criança e sua linguagem própria que é o brincar. Para se assegurar um caminho pedagógico sólido há um documento que orienta as Instituições de Educação Infantil que, ao elaborarem sua proposta pedagógica, precisam garantir o desenvolvimento integral da criança, bem como o "acesso a processos de construção de conhecimentos e a aprendizagem de diferentes linguagens, assim como o direito à proteção, à saúde, à liberdade, ao respeito, à dignidade, à brincadeira, à convivência e interação com outras crianças" (PARECER CNE/CEB, No 20/2009, p. 9).

Verifica-se através dos anos de experiência neste campo que a prática pedagógica do brincar e do ensino dos rudimentos da linguagem escrita, realizada pelos professores da Educação Infantil, principalmente nas salas de pré-escolas, repercute consideravelmente na maneira como estas crianças agem diante das situações de aprendizagem, sugeridas pelo professor, em sala de aula, nas primeiras fases do Ensino Fundamental. A falta de compreensão, aliada às percepções equivocadas, da parte de professores de Educação Infantil, em relação às situações de brincar como um direito, por um lado, e a aprendizagem dos rudimentos da linguagem escrita como uma necessidade, por outro, poderão ser responsáveis por esta dificuldade percebida nas crianças, que vale a pena investigar.

Saber, em que medida os pais compreendem as propostas de brincar proporcionadas às crianças pela escola como sendo importantes e que devem ser aproveitadas para que ocorra aprendizagem? Quais são suas principais expectativas em relação à tarefa da escola? De que forma eles têm acompanhado o trabalho do professor e questionado quanto às práticas desenvolvidas por estes? E os professores, como se sentem em relação aos pais, a escola, a sociedade sobre suas propostas de trabalho? Questões que se pretende elucidar com clareza e determinação.

É usual ouvir em discursos, da maioria dos professores de Educação Infantil, que "ensinam a linguagem escrita brincando e que o brincar é importante para a criança". O que se nota, usualmente, é que o ensino dos rudimentos da linguagem escrita se tornou a principal preocupação e o brincar fica apenas como um passatempo entre uma atividade e outra, como Benjamin (2009, p.100) já advertia que é cultural considerar o brinquedo feito "para a criança, quando não, criação da criança" e com o brincar não tem sido diferente, "tem sido visto em demasia a partir da perspectiva do adulto, exclusivamente sobre o ponto de vista da imitação". É com esta visão que muitos professores ainda percebem o brincar, como uma imitação do adulto apenas. Tem-se uma visão empobrecida e adultocêntrica desta ação tão natural e necessária à criança. Natural porque é através dessa que as crianças usam para "descobrir o seu ambiente, para aprender sobre o que acontece e porque as coisas acontecem e, prioritariamente para se divertir" (BROCK, 2011, p.37), e se acrescentaria, sem medo de errar, que aprender também está neste bojo.

Com esta pesquisa se pretende encurtar a distância entre a práxis pedagógica e a ansiedade dos pais em saber que seu filho realmente está aprendendo aquilo que em sua fase é prioritário. Não como uma pretensão de adequar as práticas pedagógicas às expectativas dos pais, mas como um repensar sobre as ações da escola sobre sua verdadeira função.

\section{Material e Métodos}

Para esta pesquisa, do ponto de vista de sua natureza se classifica como aplicada, pois objetiva "gerar conhecimentos novos úteis para o avanço da ciência sem aplicação prática prevista" (PRODANOV; FREITAS, 2013, p.51). Opta-se por uma abordagem combinando as técnicas de análise quantitativa e qualitativa em função da possibilidade de congregar identificação de variáveis específicas (métodos quantitativos) com visão global do fenômeno (métodos qualitativos). Qualitativa por esta permitir diagnosticar em profundidade a realidade a ser pesquisada, de forma a analisar as percepções colocadas pelos sujeitos, atribuindo significados, explicando em profundidade como percebem o impasse entre brincar e aprender na escola, levando em consideração a expectativa dos pais e o ponto de vista dos professores. Caracteriza-se também como quantitativa, pois significa quantificar dados obtidos por meio de informações coletadas por questionários, entrevistas, emprego de recursos e técnicas estatísticas, como porcentagem (OLIVEIRA, 2007). O cruzamento dos dados numéricos obtidos nos estratos da pesquisa foi relevante para se perceber de forma qualitativa as impressões expressadas.

Quanto aos objetivos, se classifica como pesquisa descritiva, porque "têm como objetivo primordial a descrição das características de determinada população ou fenômeno" (GIL, 2002, p.42), pois se busca levantar dados, que sustentem a compreensão do brincar e o ensino dos rudimentos da linguagem escrita na Educação Infantil, por parte dos pais e professores, através da interpretação destes dados. Quanto aos procedimentos técnicos, se caracteriza como pesquisa de campo, pois se investiga no sentido de "conseguir informações e/ou conhecimentos acerca de um problema para o qual se procura uma resposta" (PRODANOV; FREITAS, 2013, p.59).

Os sujeitos escolhidos como amostra para esta coleta de dados foram probabilísticos por agrupamento que seria "uma reunião de amostras representativas de uma população" (MENEZES; SILVA, 2001 p.32), no caso, os pais e pelo total de professores.

Os procedimentos metodológicos, as técnicas e os instrumentos utilizados para atingir os objetivos preestabelecidos foram o questionário com perguntas fechadas 
e de múltipla escolha, no máximo três questões para os pais; entrevistas com tópicos estruturados com uma pergunta aberta para os professores.

O questionário, por ser "uma das mais importantes técnicas disponíveis para a obtenção de dados, nas pesquisas sociais" (GIL, 1989 p.124), foi selecionado como a técnica mais viável a ser submetido aos pais com intuito de obter as informações necessárias e as expectativas do grupo que compõe a pesquisa. Opta-se pela entrevista, por "permitir a interação entre pesquisador e entrevistado e a obtenção de descrições detalhadas" (OLIVEIRA, 2007, p.86) sobre o tema da pesquisa. Ao interagir com cada sujeito foi possível perceber o quanto este problema é sentido e encarado no dia a dia do fazer pedagógico.

Cada professor (total de sete) foi entrevistado, individualmente, em local e horário marcado. Aos pais foi enviado, pelo professor, o questionário, totalizando dez pais por turma. Das sete turmas envolvidas na pesquisa (duas turmas de Pré I, três turmas de Pré II e duas turmas de Pré III), foram escolhidos como amostragem 10 pais por turma, em um total de 70, contabilizando as sete turmas no total. Foram enviados 70 questionários, mas foram entregues para a pesquisadora somente 54 questionários preenchidos. A pesquisa foi realizada no Centro Educacional Amerecilda Conceição Fernandes Rezende localizado na Avenida São Lourenço, número 240, Bairro São Lourenço, Campo Verde, Mato Grosso no ano de 2013.

\section{Resultados e Discussão}

\subsection{Participação dos professores e pais na pesquisa}

Foi realizada uma reunião com professores e direção do Centro Educacional Amerecilda Conceição Fernandes Rezende para se solicitar a colaboração de todos na pesquisa, bem como esclarecer sobre a importância dessa para futuras definições da Proposta Pedagógica da escola. No momento, eles receberam orientação sobre como entregar aos pais este questionário, de preferência sem imposição, aleatoriamente para os pais. Na mesma ocasião, todos os questionários foram entregues às professoras. Cada professor, em um total de sete, recebeu 10 questionários a serem distribuídos aos pais no momento em que estes viessem buscar os filhos na escola.

Na primeira parte da pesquisa, os pais deveriam marcar a fase que seu (sua) filho(a) estuda. O objetivo era perceber o nível de interesse dos pais pelos assuntos relacionados à escola. Em qual fase teria mais objeções, qual se mostraria mais recíproca com a pesquisa, qual fase de fato é mais atuante na vida escolar de seu filho. O primeiro quadro, de interesse quantitativo, demonstra as fases, a quantidade de questionários enviados, devolvidos e professores entrevistados.
Quadro 1 - Demonstrativo da quantidade de pais, fases e questionários

\begin{tabular}{|l|c|c|c|}
\hline \multicolumn{1}{|c|}{ Fases } & $\begin{array}{c}\text { Questionários } \\
\text { Enviados }\end{array}$ & $\begin{array}{c}\text { Questionários } \\
\text { Devolvidos }\end{array}$ & $\begin{array}{c}\text { Professores } \\
\text { Entrevistados }\end{array}$ \\
\hline $\begin{array}{l}\text { Pré I } \\
\text { (4 anos) }\end{array}$ & 20 & 20 & 2 \\
\hline $\begin{array}{l}\text { Pré II } \\
\text { (5 anos })\end{array}$ & 30 & 23 & 3 \\
\hline $\begin{array}{l}\text { Pré III } \\
\text { (6 anos })\end{array}$ & 20 & 11 & 2 \\
\hline Total & 70 & 54 & 7 \\
\hline
\end{tabular}

Fonte: dados da pesquisa.

Os questionários entregues para os pais pela professora no dia 19 de outubro, da turma do Pré I, 100\% foram devolvidos, devidamente preenchidos já nos primeiros três dias após a entrega. Os questionários foram entregues aos pais pelas próprias professoras titulares da sala, todos no mesmo dia. Segundo as professoras do Pré I, os pais dos alunos desta fase são bastante participativos nos assuntos, eventos e reuniões promovidos pela escola.

Os pais participantes da pesquisa dos alunos das três turmas do Pré II, apenas 76\% entregaram o questionário até o dia 29 de outubro, com dez dias de prazo. Segundo as professoras, elas não chegaram a cobrar dos pais que não devolveram o questionário. O motivo de não terem cobrado dos pais foi porque disseram que não foram elas que entregaram e sim as ADI (Auxiliar de Desenvolvimento Infantil) da sala. Por isso, os professores não sabiam para quais pais foram entregues os questionários.

O maior índice de questionários não-devolvidos foi dos pais dos alunos do Pré III. Dos 20 questionários enviados para as duas turmas, apenas $55 \%$ dos pais devolveram para as professoras.

\subsection{Posicionamento dos pais nos questionamentos}

A segunda parte do questionário, composto pelas questões 1, 2 e 3, enviado aos pais, contemplou outro objetivo. Com estas três questões se quis confirmar ou refutar parte da hipótese e ao objetivo proposto no projeto inicial, de maneira a traduzir a posição dos pais a respeito do problema. Em que medida os pais exercem pressão sobre os professores para que estes iniciem o ensino dos rudimentos da linguagem escrita na Educação Infantil. Caso a pressão, que hipoteticamente se supunha que existia fosse exercida de fato, ficaria explicitada nas três respostas, na primeira e segunda de forma implícita e na terceira questão de forma mais direta. Aspirava-se saber também o que os pais fazem para que essa cobrança seja realmente efetiva e se torne uma obrigação para os professores. Caso fosse negada esta pressão hipotética, qual é a razão da não cobrança por parte dos pais aos professores? Saber qual é a finalidade maior dos pais quando procuram os serviços do Centro Educacional, quais são suas expectativas em relação à aprendizagem de seus filhos, além de saber o que eles consideram mais importante que seus filhos recebam na Educação Infantil. 
A seguir, os dados foram analisados e a tabulação dos resultados compilados. O Quadro 2 demonstra as fases e o número de pais participantes; as questões aplicadas e suas alternativas com os seguintes valores: 1 para a alternativa mais importante, 2 para a mais ou menos importante e 3 para a menos importante. Os valores de 1 a 3 foram dispostos de forma igual para cada fase, que foi identificada por cores diferentes para diferenciar as respostas. O vermelho para identificar o Pré I, verde para identificar o Pré II e azul para o Pré III. Os valores em porcentagem foram colocados arredondando para menos. Em frente às alternativas, o número posto em cada fase representa a quantidade de pais, que marcaram tal alternativa e o valor atribuído por eles, veja-se:

Quadro 2 - Demonstrativo geral dos resultados da pesquisa com os pais

\begin{tabular}{|c|c|c|c|c|c|c|c|c|c|}
\hline Questões e Alternativas & \multicolumn{3}{|c|}{$\begin{array}{c}N^{0} \text { Pais do Pré I } \\
20\end{array}$} & \multicolumn{3}{|c|}{$\begin{array}{c}N^{0} \text { Pais do Pré II } \\
23\end{array}$} & \multicolumn{3}{|c|}{$\begin{array}{l}\text { No Pais do Pré }^{0} \\
\text { III } 11\end{array}$} \\
\hline \multicolumn{10}{|l|}{1 - Traz seu (sua) filho (a) para o Centro Educacional para: } \\
\hline Valor atribuído às alternativas & 1 & 2 & 3 & 1 & 2 & 3 & 1 & 2 & 3 \\
\hline \multirow{3}{*}{$\begin{array}{l}\text { ( ) aprender a ler e escrever } \\
\text { ( ) ter um lugar para seu filho(a) ficar enquanto você trabalha } \\
\text { ( ) brincar }\end{array}$} & 15 & 0 & 03 & 17 & 02 & 02 & 11 & 0 & 0 \\
\hline & 04 & 03 & 03 & 02 & 05 & 04 & 0 & 02 & 03 \\
\hline & 01 & 06 & 03 & 04 & 04 & 05 & 0 & 03 & 02 \\
\hline \multicolumn{10}{|l|}{2 - Para você, o mais importante na Educação Infantil é que seu filho(a): } \\
\hline Valor atribuído às alternativas & 1 & 2 & 3 & 1 & 2 & 3 & 1 & 2 & 3 \\
\hline \multirow{3}{*}{$\begin{array}{l}\text { ( ) receba cuidados } \\
\text { ( ) brinque } \\
\text { ( ) aprenda a ler e escrever }\end{array}$} & 07 & 05 & 02 & 06 & 06 & 01 & 01 & 02 & 02 \\
\hline & 01 & 03 & 06 & 01 & 05 & 07 & 0 & 02 & 03 \\
\hline & 12 & 02 & 02 & 16 & 01 & 04 & 10 & 01 & 0 \\
\hline \multicolumn{10}{|l|}{3 - Você cobra da professora que ela ensine seu (sua) filho (a) a ler e escrever? } \\
\hline \multirow{2}{*}{$\begin{array}{ll} & \text { sim } \\
( & \text { ) não }\end{array}$} & \multicolumn{3}{|c|}{09} & \multicolumn{3}{|c|}{05} & \multicolumn{3}{|c|}{08} \\
\hline & \multicolumn{3}{|c|}{11} & \multicolumn{3}{|c|}{18} & \multicolumn{3}{|c|}{03} \\
\hline \multicolumn{10}{|l|}{ a) Em caso afirmativo, como tem feito essa cobrança? } \\
\hline \multirow{3}{*}{ 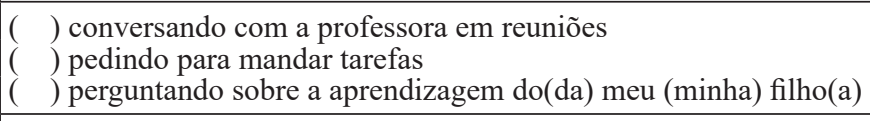 } & \multicolumn{3}{|c|}{06} & \multicolumn{3}{|c|}{03} & \multicolumn{3}{|c|}{04} \\
\hline & \multicolumn{3}{|c|}{0} & \multirow{2}{*}{\multicolumn{3}{|c|}{0}} & \multicolumn{3}{|c|}{02} \\
\hline & \multicolumn{3}{|c|}{07} & 07 & & & \multicolumn{3}{|c|}{07} \\
\hline \multicolumn{10}{|l|}{ b) Em caso negativo, por que não cobra? Justifique. } \\
\hline & \multicolumn{3}{|c|}{$\begin{array}{c}\text { Pais que } \\
\text { justificaram } \\
11\end{array}$} & \multicolumn{3}{|c|}{$\begin{array}{l}\text { Pais que } \\
\text { justificaram } \\
15\end{array}$} & \multicolumn{3}{|c|}{$\begin{array}{c}\text { Pais que } \\
\text { justificaram } \\
03\end{array}$} \\
\hline
\end{tabular}

\section{Fonte: Dados da pesquisa.}

Este demonstrativo geral do resultado da pesquisa com os pais se mostra um pouco complexo pelo fato de se ter contemplado todas as informações possíveis oferecidas pelos pais. Por esta razão, para melhor compreensão e visualização dos dados descritos no Quadro 2, se analisam através de gráficos, cada questão proposta, visualizando melhor o valor atribuído pelos pais nas Fases I, II e III.

\subsection{Finalidade do Centro Educacional na visão dos pais}

No gráfico da Figura 1 analisa-se o primeiro questionamento com o objetivo de saber para qual finalidade os pais utilizam os serviços do Centro Educacional. Com isto se soube quais são suas expectativas e prioridades na vida escolar do seu filho e o que esperam da escola, deixando explícitas suas concepções.

Figura 1 - Traz seu (sua) filho (a) ao Centro Educacional para:

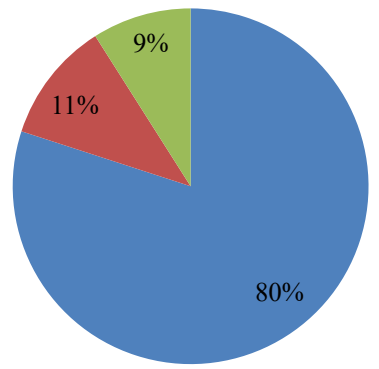

- Aprender a ler e escrever

- Ter um lugar pra ficar

Brincar

Fonte: dados da pesquisa.
A alternativa cujos pais marcaram com (1) ou com (X), considerada pelos participantes das três fases como finalidade primeira da sua utilização dos serviços educacionais do Centro foi a primeira: “Aprender a ler e escrever", definida pela cor azul no gráfico. Dos 54 pais, 43 deles, ou seja, 79\% consideram aprender a ler e escrever na Educação Infantil como a maior razão pela qual trazem seus filhos à escola. Apenas 11\% dos pais consideraram a alternativa "ter um lugar para seu filho (a) ficar enquanto você trabalha" como sendo de maior finalidade e $9 \%$ apenas, destes pais, assinalaram o "brincar".

Ficou explícito, nesta primeira pergunta, que a alternativa "Aprender a ler e escrever" foi eleita pelos pais como a mais importante, sendo que do Pré I, 15 pais marcaram esta alternativa, cerca de $75 \%$ do total; do Pré II foram 17 pais, correspondente a $73 \%$ do total de participantes e no Pré III $100 \%$ dos pais marcaram esta alternativa.

"Ter um lugar para seu filho(a) ficar enquanto você trabalha" foi eleita como mais importante na visão de 4 pais do Pré I e 2 pais do Pré II. Apenas 1 pai do Pré I e 4 pais do Pré II elegeram "brincar" como a opção mais importante para seus filhos.

A grande expectativa dos pais, na primeira questão, sem sombra de dúvidas, é que seu filho ou filha aprenda a ler e 
escrever, mesmo no Pré I. A que isso se deve? Para eles, o que é ler e escrever nesta fase? Mesmo sendo em uma Instituição de Educação Infantil, cuja principal missão é cuidar e educar, esperam tanto que seus filhos aprendam a ler e escrever? Que associação fazem entre o Centro Educacional com as escolas de Ensino Fundamental?

De certa forma, as pessoas, de um modo geral, associam o aprender a ler e escrever com a escola. E creche não deixa de ser uma escola, a primeira escola que o filho frequenta. É histórico, cultural e até natural para as pessoas, principalmente, com pouco grau de instrução escolar, pensar que quando se vai para a escola só pode ser para aprender a ler e escrever, cujas funções são atribuídas como responsabilidade unicamente da escola e não da família.

Como enfatiza Lerner (2002, p.19): "Como a função (explícita) da instituição escolar é comunicar saberes e comportamentos culturais às novas gerações, a leitura e a escrita existem nela para ser ensinadas e aprendidas", e é isso que os pais esperam da escola, mesmo de uma Instituição de Ensino Infantil, por esta se caracterizar como uma Instituição de Ensino. Esse ler e escrever para os pais, conforme se pode perceber no depoimento dado nos questionários, pensam leitura e escrita em uma forma bem tradicional, comumente usada no senso comum em que se codifica, decodifica e se memorizam as letras, aprendendo a escrever o nome e as letras do alfabeto.

Desde o momento que uma criança inicia sua vida escolar é normal, da parte dos pais, pensarem que seu filho irá aprender na escola o que não é, em sua totalidade, possível a família ensinar. Esse aprender, na concepção de muitos pais, está relacionado, principalmente, à leitura e à escrita, pois outras formas de aprendizagem não são consideradas como relevante para eles, por exemplo, o brincar. Prova disso é que apenas $9 \%$ dos pais, nesta pesquisa, consideraram o brincar como mais importante para seus filhos na Educação Infantil e $91 \%$ consideram esta ação não como uma responsabilidade da escola e, talvez, por isso não consideram importante. Por qual razão os pais não valorizam o brincar como uma ação de aprendizagem praticada pela escola?

As razões para que os pais desvalorizem as ações lúdicas praticadas pela escola suponha-se que seja, talvez, fomentada pelos próprios professores que "estimulam implicitamente esta noção em sua organização das atividades da classe" (MOYLES, 2002, p.25). Os professores precisam primeiramente acreditar que "a brincadeira é a ferramenta mais valiosa para a aprendizagem" (BROCK, 2011) e, saber articular com os pais e toda a comunidade escolar a proposta do brincar como geradora também de aprendizagem. Os professores "precisam estar aptos a explicar a sua proposta de experiências de brincadeira para uma audiência mais ampla" (idem), neste caso, os pais. Os pais têm toda razão de "não valorizar" e, ao mesmo tempo, questionar estas situações lúdicas, que muitas vezes não se diferenciam do tipo do brincar que seus filhos praticam em casa.

Ao se realizar o próximo questionamento, o objetivo foi saber, através das três alternativas apresentadas, qual dessas os pais consideram mais importante para seu filho na Educação Infantil. Se é receber cuidados; se é brincar; ou aprender a ler e escrever com o intuito de confirmar ainda mais o objetivo posto na questão três.

Conforme o gráfico da Figura 2, as alternativas "receba cuidados" e "brinque" foram consideradas pelos pais de menor importância. Enquanto a terceira, "aprender a ler e escrever", representada pela cor azul, assinalaram como a mais importante.

Figura 2 - Para você, o mais importante na Educação Infantil é que seu filho(a):

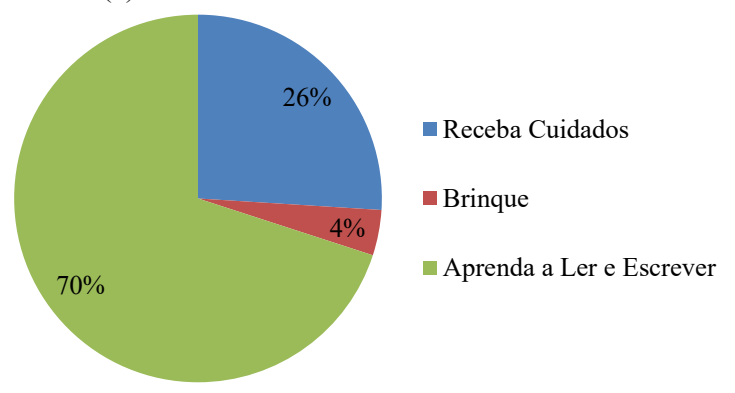

Fonte: dados da pesquisa.

De 54 pais participantes, consideraram o nível 1 de maior importância para as alternativas: "brinque" com 4\%; "receba cuidados" com $26 \%$ e $70 \%$ consideraram "aprender a ler e escrever" como a alternativa mais importante no seu ponto de vista.

Ler e escrever é o requisito mais importante na Educação Infantil para $60 \%$ dos pais do Pré I. Considerando ser o primeiro ano desta fase na escola e, de certa forma, em uma visão do senso comum, estariam fora da idade para isso. Mesmo assim se percebe esta preocupação, que seus filhos aprendam a ler e escrever o mais cedo possível. Para os pais dos alunos do Pré II, 70\% também consideram ler e escrever uma ação importante na Educação Infantil. Dos alunos do Pré III, 91\% dos pais marcaram esta alternativa.

Para certos grupos sociais, a leitura e a escrita é encarada "como uma simples garantia de sobrevivência na sociedade" (CAGLIARI, 2009, p.87). Talvez, para este grupo, a leitura e a escrita sejam consideradas dessa forma, por evidenciarem esta preocupação tão precocemente aos seus filhos.

Pode-se perceber também que receber cuidados é muito mais importante para estes pais do que brincar. De certa forma, o brincar é percebido, diferentemente, tanto pelos pais quanto pela comunidade escolar, "o modo como a brincadeira é percebida em qualquer comunidade se dá em função do modelo de infância daquela comunidade e de modo como ele se desenvolveu socialmente" (BROCK, 2011, p. 61).

O brincar na escola, pelo que está posto, não tem para os pais muita relevância. De 54 pais, apenas dois marcaram "brincar" como uma ação importante para seus filhos. Dos 
pais participantes, $96 \%$ não consideram esta alternativa importante. Por esta razão, fica evidente que, na visão dos pais, o "brincar" na escola não é diferente do brincar que seus filhos se envolvem em casa, por isso não veem como uma ação importante que precisa ser valorizada pela escola. Embora se saiba que todas as relações educativas, conforme alertam os Parâmetros de Qualidade para a Educação Infantil (2008, p. 17): "são perpassadas pela função indissociável do cuidar/ educar, tendo em vista os direitos e as necessidades próprios das crianças no que se refere à alimentação, à saúde, à higiene, à proteção e ao acesso ao conhecimento sistematizado".

Segundo o mesmo documento, a função de cuidar é bem transparente nas Instituições de Educação Infantil no Brasil, " em muitas delas ainda predomina um modelo de atendimento voltado principalmente à alimentação, à higiene e ao controle das crianças" (p. 18). É esta a visão que os pais e a comunidade, em geral, têm das Instituições de Educação Infantil. Já em relação ao acesso ao conhecimento sistematizado, as Instituições Infantis ainda terão muito que crescer e aprender.

A terceira questão a ser analisada: "Você cobra da professora que ela ensine seu (sua) filho (a) a ler e escrever?" Se constitui no objetivo maior desta pesquisa com os pais. Com este questionamento se aspirava saber, de forma mais direta, se de fato os pais exercem pressão sobre os professores para que estes ensinem seus filhos a ler e escrever. De forma subentendida, esta questão praticamente foi respondida pelas questões 1 e 2 , mas queria-se perceber quantos pais deixam isso claro, sem constrangimentos. A questão proposta no questionário do tipo fechada tinha como resposta "sim" ou "não", para que assinalassem com X, veja o gráfico:

Os pais que dizem "não" cobrar da professora que ela ensine seu filho a ler e escrever representa cerca de $59 \%$ dos participantes, ou seja, 32 pais. Os pais que responderam "sim", são 22 ao todo que cobram da professora que ensine seu filho a ler e escrever e representam $41 \%$ dos pesquisados. Destes, 32 pais que responderam "não", aproximadamente $34 \%$ do Pré I, $56 \%$ do Pré II, e 10\% do Pré III. Dos 22 pais que responderam "sim", aproximadamente $41 \%$ são do Pré I, 23\% do Pré II e $36 \%$ do Pré III.

Analisando as repostas por Fases do total de pais, que responderam o questionário, em cada fase, verifica-se que: os pais que mais cobram da professora a leitura e a escrita são os pais do Pré III, com 72\%; seguidos dos pais do Pré I com 45\%; e finalmente, os pais do Pré II com $21 \%$. Os pais que não cobram da professora são $55 \%$ do Pré I; $78 \%$ do Pré II e $27 \%$ do Pré III.

Se for considerar a porcentagem das respostas "sim" ou "não" da terceira questão fica evidente que a maioria dos pais não exerce pressão sobre os professores pelo fato de que $59 \%$ deles marcaram a resposta "não", que não cobram dos professores que ensinem a leitura e a escrita e somente $41 \%$ marcaram que "sim". Embora essa diferença de 59\% para $41 \%$ não seja tão relevante, apenas $18 \%$.

\subsection{A verdadeira expectativa dos pais}

Ao se analisar as respostas da primeira e da segunda questão demonstradas no gráfico 1 e 2, "aprender a ler e escrever" é a maior das expectativas dos pais. De 54 pais participantes, 79\% consideram que "Aprender a ler e escrever" é a maior razão para trazerem seus filhos ao Centro Educacional. Na resposta para a segunda questão: "Para você, o mais importante na Educação Infantil é que seu filho (a):” fica evidente também a preferência de $70 \%$ dos pais pela alternativa: "Aprender a ler e escrever".

Pode-se também considerar o fato de que na terceira questão a resposta "sim ou não", de forma fechada e restrita não abrange a expectativa dos pais, tão evidentes como na primeira e na segunda questão. Por ser uma questão mais relacionada à prática e estar vinculada à forma como os pais se relacionam com os professores, confirmar ou não que cobra do professor, não quer dizer que aprender a ler e escrever não representa a maior expectativa deles em relação à aprendizagem de seus filhos.

Dos 32 pais que assinalaram que "não" cobram, 29 elaboraram uma justificativa do porquê da não cobrança; destes, 14 pais ( 7 do Pré I e 7 do Pré II) justificaram utilizando-se de expressões semelhantes. Tomam-se seis das mais significativas como exemplo, o Quadro 3.

Quadro 3 - Justificativas dos pais pela não cobrança da leitura e da escrita nas Fases I e II.

\begin{tabular}{|l|l|}
\hline Pais & \multicolumn{1}{|c|}{ Respostas } \\
\hline Pré I & $\begin{array}{l}\text { "Tudo tem a hora certa, não adianta cobrar se não é a } \\
\text { hora." }\end{array}$ \\
\hline Pré I & $\begin{array}{l}\text { "Sabe-se que nesta faixa etária não é obrigação do } \\
\text { professor alfabetizar." }\end{array}$ \\
\hline Pré I & "Porque acho ele muito novo." \\
\hline Pré II & $\begin{array}{l}\text { "Porque ainda é muito cedo para a idade, ele vai ter } \\
\text { tempo para aprender, agora quero que ele curta ser } \\
\text { criança." }\end{array}$ \\
\hline Pré II & $\begin{array}{l}\text { "Porque entendemos que a Educação Infantil não pode } \\
\text { ser sobre pressão." }\end{array}$ \\
\hline Pré II & $\begin{array}{l}\text { "Porque acredito que é uma fase de apresentação da } \\
\text { leitura e da escrita e a professora sabe o tempo certo } \\
\text { para cada fase." }\end{array}$ \\
\hline
\end{tabular}
Fonte: Dados da pesquisa.

As razões para estes pais não cobrarem do professor é simples. Acreditam que os filhos ainda não estão na idade certa para aprender a ler e escrever, que são muito novos, acham que não é obrigação da professora ensinar nesta fase, etc.. Eles partem da ideia de que a leitura e a escrita é uma habilidade que pode só pode ser ensinada na escola e que tem a idade e o momento certo para começar, e quem decide é o adulto. Ideia esta recorrente no senso comum para muitos pais e, infelizmente, para muitos professores. Como diz Telma Weisz (2002, p. 19), este ponto de vista "adultocêntrico" que é:

[...] a forma pelo qual se costuma conceber a aprendizagem das crianças a partir da própria perspectiva do adulto que já domina o conteúdo... Desta forma, não é possível 
compreender o ponto de vista do aprendiz, pois não se pode "enxergar" o objeto de seu conhecimento com os olhos de quem ainda não sabe.

Este pensamento parte da ideia de que quem decide quando e o que a criança vai aprender é o adulto. Segundo Weisz (id. 2002, p.19), este conceito "gera um tipo de procedimento pedagógico que dificulta o processo de aprendizagem", principalmente, para as crianças advindas de famílias menos favorecidas, que precisam desse conhecimento transmitido pela escola por terem menos experiências com conteúdos escolares e por terem somente na escola a oportunidade de contato com material escrito. Por acreditarem nesta perspectiva, julgam desnecessário ou impróprio cobrar do professor que ofereça oportunidades de leitura e escrita aos seus filhos na Educação Infantil.

Porém na justificativa de 15 pais ( 4 do Pré I, 8 do Pré II e 3 do Pré III), dos 29 que justificaram, se nota a diferença do discurso ao justificarem o porquê "não" cobram dos professores o ensino da leitura e da escrita aos seus filhos. Tal conclusão fica evidenciada nas respostas dadas pelos pais. As 15 justificativas apresentam respostas semelhantes e foram escolhidos dois exemplos de cada Fase, as mais ricas em detalhes para a seguinte análise:

Quadro 4 - Justificativas dos pais pela não cobrança da leitura e da escrita nas Fases I, II e III.

\begin{tabular}{|l|l|}
\hline Pais & Respostas \\
\hline Pré I & $\begin{array}{l}\text { Não cobro porque vejo que elas ensinam e porque eu } \\
\text { pergunto para minha filha o que ela fez na escola e o } \\
\text { que ela aprendeu a cada dia }\end{array}$ \\
\hline Pré I & $\begin{array}{l}\text { Porque sei que ela está lá para esta finalidade e também } \\
\text { percebo melhoras no seu desenvolvimento. O processo } \\
\text { de ler e escrever estão acontecendo gradativamente }\end{array}$ \\
\hline Pré II & $\begin{array}{l}\text { Não cobro porque estou satisfeita com o trabalho da } \\
\text { professora }\end{array}$ \\
\hline Pré II & $\begin{array}{l}\text { Porque sei que ela está se alfabetizando. Ela já faz seu } \\
\text { nome, conhece as vogais e as letras do alfabeto todo }\end{array}$ \\
\hline Pré III & $\begin{array}{l}\text { Não cobro porque estou contente com o trabalho da } \\
\text { professora. Minha filha está aprendendo aos poucos e } \\
\text { ela adora fazer as tarefas, eu estou sempre junto }\end{array}$ \\
\hline Pré III & $\begin{array}{l}\text { Não cobro porque a professora da minha filha é uma } \\
\text { professora muito dedicada aos seus alunos, por isto } \\
\text { não vejo a importância de cobrar. Eu só tenho que } \\
\text { agradecê-la }\end{array}$ \\
\hline
\end{tabular}

Fonte: Dados da pesquisa.

Ao se analisar as respostas destes 15 pais, eles demonstram que estão satisfeitos com o trabalho de leitura e escrita desenvolvido pelas professoras do Centro Educacional e que não sentem a necessidade de cobrar. Não cobram, ou não pressionam os professores pelo simples fato de que o professor já desempenha bem este papel. Talvez, se a escola não sanasse suas expectativas em relação a este eixo, com certeza, cobrariam dos professores. Isto confirma a expectativa dos pais em relação à leitura e à escrita postas nas questões 1 e 2 do questionário.

A escola, bem como os professores, tradicionalmente, se sente na obrigação de ensinar a ler e escrever, talvez, não pela pressão efetiva dos pais, como se pode perceber nas respostas dadas, mas por uma suposta pressão sentida por eles próprios. Percebe-se também, à medida que a criança e a família se identificam com a rotina escolar, isso permite certa tranquilidade e confiabilidade dos pais em relação às tarefas intrínsecas da escola, por esta desenvolver aquilo que esperam e que a sociedade determina.

Se estes 15 pais, que dizem não cobrar dos professores que ensinem seus filhos a ler e escrever, porque os professores já realizam este trabalho e não sentem a necessidade de cobrarem, fossem diminuídos do total de 32, que assinalaram "não" na questão 3, restaria então apenas 17 pais, que não cobram realmente dos professores de forma alguma. E se somar estes 15 pais aos 22, que dizem cobrar, se somaria 37 pais que realmente cobrariam dos professores se estes não realizassem este trabalho.

Diante desta análise e das justificativas, pode-se concluir que os pais, em sua grande maioria, exercem pressão sobre os professores para que iniciem o ensino dos rudimentos da linguagem escrita. A hipótese se confirma ainda mais positiva se apenas diminuir dos 32 pais, que dizem cobrar, estes 15 que não cobram, por não verem necessidade, pois o professor já ensina, restariam apenas 17 que realmente cobrariam. Então, os 22 pais que afirmaram cobrar seriam a maioria.

De que forma os pais procedem para cobrar do professor, explicitamente, que este ensine seu filho a ler e escrever? As formas mais utilizadas por estes pais, que afirmam cobrar dos professores, que ensinem seus filhos a ler e escrever, vê-se no gráfico da Figura 3.

Figura 3 - Em caso afirmativo, como tem feito essa cobrança?

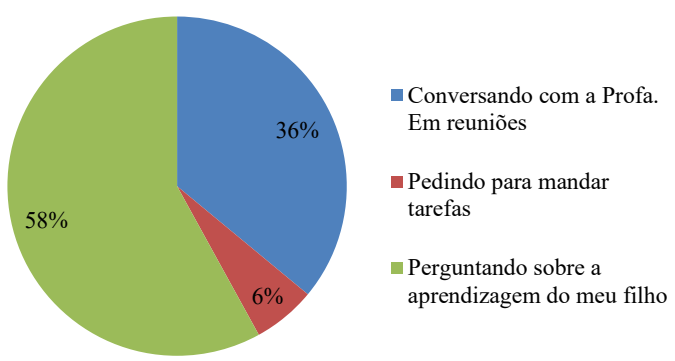

Fonte: dados da pesquisa.

Mesmo os pais que afirmaram que "não" cobram os professores para ensinar a ler e escrever, 14 deles marcaram uma das alternativas da letra (a) da segunda parte da questão 3 com X. Alguns marcaram mais de uma das alternativas. Este fato prova ainda mais que, de forma não expressa, exercem pressão sobre os professores.

Todas as marcações foram consideradas na somatória das alternativas. Dessa forma, o número dos que marcaram "sim" não confere com o número evidenciado no Quadro 2, nas três alternativas.

Dos pais participantes, 13 dizem cobrar "conversando com a professora em reuniões", 2 "pedindo para mandar tarefas" e 21 "perguntando sobre a aprendizagem do (da) meu (minha) filho (a)". 
A forma mais utilizada pelos pais para efetivarem a cobrança sobre os professores é a sugestão três: "perguntando sobre a aprendizagem do (da) meu (minha) filho (a)". Os pais realmente interessados pela aprendizagem de seu filho devem fazer questão de questionar o professor, de saber o que realmente seu filho está aprendendo. Cabe ao professor segurança e convicção de seu trabalho e ter bons argumentos para tranquilizar os pais de que a forma com que realiza seu trabalho é correta e importante. Ao professor é aconselhável demonstrar sensibilidade à expectativa dos pais, porém ceder a estas expectativas é não estar seguro do trabalho que realiza.

Os professores sentem alguma forma de cobrança por parte dos pais? Como percebem esta cobrança? Como isto é resolvido entre as partes envolvidas no processo educativo?

\subsection{A suposta pressão sobre os professores}

Com o escopo de averiguar se os professores se sentem pressionados por alguém, principalmente os pais, para dar início ao ensino da linguagem escrita na Educação Infantil, este questionamento, de fundo qualitativo, foi necessário e importante para esta pesquisa. Há interesse em perceber se a pressão subentendida nos depoimentos dos pais, na realidade, chega a ser sentida pelos professores e como conseguem lidar com isso no seu dia a dia da sala e aula. Para se verificar o problema posto, segue-se com a mesma metodologia por quadros, observando os depoimentos de cada um dos envolvidos no processo e, posterior análise dissertativa sobre as impressões observadas. Como segue o Quadro 5:

Quadro 5 - Pressão no processo ensino-aprendizagem na percepção dos professores

\begin{tabular}{|c|c|}
\hline Professor & $\begin{array}{l}\text { Em sua prática pedagógica sente-se pressionada para iniciar o ensino dos rudimentos da linguagem escrita na } \\
\text { Educação Infantil? Por quem? De que forma sente isso? Como tem resolvido isso? }\end{array}$ \\
\hline P. 1 & $\begin{array}{l}\text { Eu falo assim, que às vezes, a sociedade em si acaba cobrando que a Educação Infantil tem que alfabetizar, porque existe } \\
\text { aquele comparativo de escola. ... Então eu acredito que a gente acaba tendo essa pressão, mas não que isso force a gente } \\
\text { a realizar uma coisa que a gente não quer realizar, entendeu. Parte do meu eu assim, essa pressão, eu vejo a capacidade } \\
\text { que eles têm, porque hoje as crianças elas têm um rendimento, elas já vem de uma sociedade que esta exigindo mais nesse } \\
\text { sentido, mas não que a professora tem que ensinar a ler e escrever... Os pais não, isso não... }\end{array}$ \\
\hline P. 2 & $\begin{array}{l}\text { Antigamente, eu sentia muito no pré III sim, eu sentia muito a angústia dos pais... Que eles tinham que aprender a } \\
\text { escrever, no ler eles não falavam tanto, mais era escrever, escrever e escrever. ...Eu falava que tinha que respeitar o } \\
\text { desenvolvimento da criança, ela não estava preparada. Agora esses daqui, não (pré I), não, não cobram. }\end{array}$ \\
\hline P. 3 & $\begin{array}{l}\text {...quem mais cobra são os pais, porque eles anseiam que os filhos, principalmente, quando chega no Pré III, saiam daqui } \\
\text { lendo e escrevendo. Eles perguntam principalmente na reunião, professora meu filho vai sair daqui lendo, vai sair daqui } \\
\text { escrevendo? Eu falo, de acordo com as normas do Centro Educacional, ...aqui nós propiciamos um ambiente alfabetizador } \\
\text { que ajudará o seu filho a estar despertando para a escrita. Eles não questionam mais. Talvez por medo, eu não sei... }\end{array}$ \\
\hline P. 4 & $\begin{array}{l}\text {.... gente sente no ar que alguma... sabe, que há uma exigência, ninguém nunca me falou: Não! Você tem que fazer assim, } \\
\text { assim, assim! Mas você sente assim, pelo andamento da carruagem, sente que você é levada a fazer isso. ...sinto assim } \\
\text { que paira no ar essa questão... Parte..., da gestão, da secretária de Educação, mais isso daí....Bom, não tenho resolvido, eu } \\
\text { tenho levado, não tem uma coisa resolvida, vai levando, vai sabe, fazendo o que posso, o que está ao alcance... }\end{array}$ \\
\hline P.5 & $\begin{array}{l}\text { A gente tem o planejamento da gente, conforme for o planejamento por bimestre tem as regras, os conteúdos, mas nunca } \\
\text { senti assim. Sempre na primeira reunião já falo para eles..., eu to ali para educar, para brincar e ensinar a primeira letrinha } \\
\text { do nome, mas não é obrigatório. Os números também ensino pra eles escrever. Porque sempre na primeira reunião eu já } \\
\text { informo, pré I não é alfabetização, não sai sabendo ler e escrever, que eles estão ali para aprender a se socializar. }\end{array}$ \\
\hline P. 6 & $\begin{array}{l}\text { Às vezes, os pais cobram, ...este ano vários pais começaram a cobrar. Eu comecei a explicar para eles que ainda não é } \\
\text { tempo de começar a ensinar a ler e escrever, que eles vão ter muito tempo. }\end{array}$ \\
\hline P.7 & $\begin{array}{l}\text {... eu sinto pressionada por mim mesma, eu tenho que fazer. ... eu sou uma professora, eu escolhi essa profissão eu tenho } \\
\text { que passar as ferramentas que eles têm que aprender. Não. Por parte de pai nunca senti nada, entendeu. }\end{array}$ \\
\hline
\end{tabular}
Fonte: Dados da pesquisa.

Pode-se dizer, a partir dos depoimentos, que em geral a maioria se sente, de alguma forma, pressionada. Uma se sente pressionada pela sociedade que a cada dia valoriza os que sabem mais, que sabem utilizar quanto mais cedo as ferramentas modernas de comunicação, principalmente, a escrita. Outras se sentem pressionadas pelos pais que já chegam exigindo que seus filhos aprendam a ler e escrever para dar conta desta visão de sociedade; vence quem é o melhor. Outra, se sente pressionada pelo andamento do processo, pelo sistema vigente que leva a isso, a alfabetizar precocemente, seguindo as tendências modernas, modismos e comparações, que aparecem no processo educativo.

E outra, que pressionada por ela mesma, pelo fato de ser professora, percebe que é sua missão intrínseca ensinar as ferramentas (leitura e escrita) que a sociedade exige cada vez mais cedo. Apenas uma delas afirma não se sentir pressionada pelos pais, pelo motivo de que, já na primeira reunião, esclarece os objetivos da fase e as capacidades que serão desenvolvidas, bloqueando assim uma futura pressão e amenizando a expectativa dos pais.

A educação segue os ditames da sociedade atual, capitalista e individualista, vence quem é o melhor. O que mais existe nas Instituições de Ensino é a pressão que o próprio sistema de ensino vigente exerce sobre o professor em função das comparações e avaliações das práticas pedagógicas. As comparações entre professores pela própria direção da escola: porque os alunos da professora P.1 já sabem escrever o alfabeto e os alunos da professora P.2 não sabem? Comparações entre os próprios professores: meus alunos já sabem escrever o nome e os seus? 
Diante disso, o professor, que não tem segurança naquilo que desenvolve, se sente muitas vezes incapaz e começa a reproduzir práticas das quais não acredita só para se igualar ao outro professor ou seguir um modelo estabelecido. A direção e até mesmo os professores, em momentos de reunião pedagógica, tecem comentários sobre a aprendizagem dos alunos da classe A com os alunos da classe B. Entre pais que chegam à escola querendo saber por que a professora do filho da vizinha manda muita tarefa e a professora do seu filho não. São estas formas de pressão que "...a gente sente no ar que ... há uma exigência" e o professor, acaba se pressionando: "Parte do meu eu assim, essa pressão...", como revela a professora P.1.

Contudo, mesmo se sentindo pressionadas por alguém, de alguma forma, as professoras não se deixam levar por esta pressão como se tem evidência na fala da P.1: “... mas não que isso force a gente a realizar uma coisa que a gente não quer realizar, entendeu.". Isso demonstra que a professora se sente segura em relação a sua prática, o que muitas vezes não é o que ocorre com outras profissionais. Esta segurança fica transparente na fala da professora P.3: "Eu falo, de acordo com as normas do Centro Educacional, ...aqui nós propiciamos um ambiente alfabetizador que ajudará o seu filho a estar despertando para a escrita.”. Estas explicações são importantes para os pais se sentirem seguros em relação ao ensino oferecido aos seus filhos. Quando o professor consegue transmitir essa segurança aos pais, com certeza, eles terão mais confiança no trabalho desenvolvido por ela.

\section{Conclusão}

A sociedade vive um momento histórico, em que tanto as famílias quanto as Instituições Educacionais Infantis sofrem transformações. O que mais tem se discutido ultimamente, por educadores e estudiosos, é a pertinência ou não de iniciar nesta etapa o ensino da linguagem escrita. As crianças estão em contato com o mundo da escrita cada vez mais cedo, através da hipermídia, dos links, dos jogos virtuais, dos clipes por meios eletrônicos, mesmo as que moram em zonas rurais. Vive-se em uma sociedade na qual a vida social está organizada em torno da escrita e do grande avanço tecnológico dos meios de comunicação. As Instituições de Ensino, pressionadas pelas avaliações internas e externas, estão preocupadas com os indicadores e com a necessidade de otimizar oportunidades, tornando mais rápido e garantido o ingresso do indivíduo na vida produtiva.

Este cenário tem influenciado a antecipação do processo de alfabetização nas Instituições de Educação Infantil, de um modo geral, em que o ensino da leitura e da escrita se assemelha ao ensino formal, no qual a linguagem escrita é reduzida a um código de transcrição gráfica, trazendo consequências sem precedentes que serão percebidas alguns anos depois, em jovens e adultos que não leem, que não escrevem e que só reproduzem. A escola precisa acompanhar essas mudanças na sociedade, porém convém ser cautelosa e responsável com o sujeito de direito, que é a criança.

As escolas de Educação Infantil estão mudando sua forma de atuação, não mais como centros de assistência às mães pobres e sim como Centros Educacionais voltados ao atendimento às crianças em todos os aspectos do seu desenvolvimento. Diante disso, os gestores precisam garantir a inserção das crianças desta etapa em um mundo letrado, considerando seus modos de ser criança, suas características e necessidades.

É aconselhável buscar um consenso no entendimento, principalmente, da escola com seu corpo docente, quanto da família em relação ao ensino e aprendizagem, que não precisa ser um processo apressado e imposto, porque é necessário que, antes da imposição do código escrito, a criança aprenda o valor incomunicável da linguagem através das suas diferentes modalidades. Antes de desenvolverem as habilidades manuais da escrita, que lhes deem oportunidades para produzirem textos orais, leitura de imagens, brincar com palavras que têm significado para elas nos diferentes espaços e tempos de sua vida. Naturalmente, cada coisa em seu tempo, em seu espaço, em sua ordem.

Chegar a uma compreensão de que ambos os temas são considerados distintos, porém indissociáveis no processo de aprender é uma tarefa urgente da escola e do professor. É urgente a necessidade do professor em conhecer e se aprofundar nos pressupostos pedagógicos do brincar, manterse informado e formado, buscar construir em sua prática pedagógica uma práxis crítica, que o ajude na compreensão e na valoração do brincar da criança como uma função intrínseca do aprender, construindo em seu fazer pedagógico as bases sólidas nas pesquisas contemporâneas, a fim de satisfazer as necessidades e interesse das crianças, tendo a firme convicção de que a criança é capaz de aprender pelo brincar.

Constatou-se que os pais exercem pressão sobre os professores, mesmo que de forma implícita, não diretiva, mas que isso faz uma grande diferença no agir pedagógico do professor, pois este começa a se preocupar sobre a razão com que estes pais estão fazendo tal questionamento. $\mathrm{O}$ medo da comparação do seu trabalho induz o professor a realizar práticas nas quais muitas vezes não acredita ou não tem propriedade, somente para satisfazer os pais ou a direção da escola.

É perfeitamente normal a família, de início, saber o que a escola oferece ao seu filho, a qualidade dos serviços prestados por esta instituição e a eficiência e competência do professor. Se a escola estiver apta a esclarecer e os professores transmitirem segurança e domínio em sua proposta, as dúvidas e os anseios diminuem, gradativamente, à medida que a família percebe o desenvolvimento da criança.

Muitas vezes, o que acaba acontecendo é o professor se sentir na obrigação de alfabetizar, "pelo andamento da carruagem, você é levada a fazer isso", seguindo modelos estereotipados de ensino para satisfazer a expectativa dos pais e da sociedade ou as exigências da própria escola. 
Pode-se perceber uma angústia e, também, uma imposição sobre ela mesma no depoimento da professora P.7, pelo simples fato de ser professora: “...eu sou uma professora, eu escolhi essa profissão eu tenho que passar as ferramentas que eles têm que aprender.". Esta visão "adultocêntrica" do processo de ensino e aprendizagem, em que é o adulto quem decide o que e quando ensinar ainda está presente na forma de pensar de muitos professores, em que o ensino está centrado no professor e não na criança. Com esta visão, a Educação Infantil traz consequências para a ação do processo ensino e aprendizagem da linguagem escrita, que poderá ficar comprometido.

\section{Referências}

BENJAMIN, W. Reflexões sobre a criança, o brinquedo e a educação. São Paulo: Duas Cidades, 2009.

BRASIL. Referencial Curricular Nacional para Educação Infantil. Brasília, 1998. v.1/3.

BRASIL. Ministério da Educação. Secretaria de Educação Básica. Parâmetros Nacionais de qualidade para a Educação Infantil/Ministério da Educação. Secretaria de Educação Básica. Vol. 1 e vol. 2. Brasília: ME/SEB, 2008.

BRASIL. CNE/CEB. Parecer n ${ }^{\circ}$ 20, de 11 de novembro de 2009. Revisão das Diretrizes Curriculares Nacionais para a Educação Infantil. Diário Oficial da União, Brasília, DF, 9 de dezembro de 2009a.

BRASIL. Resolução $n^{\circ}$ 5, de 17 de dezembro de 2009. Fixa as Diretrizes Curriculares pra Educação Infantil. Diário Oficial da União, Brasília, DF, 18 dez de 2009b .

BRASIL. Ministério da Educação. Secretaria de Educação
Básica. Lei no 9.394/96 Lei de Diretrizes e Bases da Educação Nacional. Centro de Documentação e Informação. Edições Câmara. Brasília | 2010.

BROCK, A. Brincar: aprendizagem para a vida. Porto Alegre: Penso 2011.

CAGLIARI, L.C. Alfabetização \& linguística. São Paulo: Scipione, 2009.

FERREIRO, E. Com todas as letras. São Paulo: Cortez,

GIL, A.C. Métodos e técnicas de pesquisa social. São Paulo: Atlas, 1989.

GIL, A.C. Como elaborar projetos de pesquisa. São Paulo: Atlas, 2002.

LERNER, D. Ler e escrever na escola: o real, o possível e o necessário. Porto Alegre: Artmed, 2002.

MOLYLES, J.R. Só brincar? O papel do brincar na educação infantil. Porto Alegre: Artmed, 2002.

MENEZES, E.M.; SILVA, E.L. Metodologia da pesquisa e elaboração de dissertação. Florianópolis: UFSC, 2001.

OLIVEIRA, M.M. Como fazer pesquisa qualitativa. Petrópolis: Vozes, 2007.

PRODANOV, C.C.; FREITAS, E.C. Metodologia do trabalho científico: métodos e técnicas da pesquisa e do trabalho acadêmico. Novo Hamburgo: Feevale, 2013.

SARAIVA, J.A. Palavras, brinquedos e brincadeiras: cultura oral na escola. Porto Alegre: Artmed, 2011.

WEISZ, T.; SANCHES, A. $O$ diálogo entre o ensino e a aprendizagem. São Paulo: Ática, 2002.

ZILBERMAN, R. A literatura infantil na escola. São Paulo: Global, 2003. 